\title{
A INFLUÊNCIA DA EDUCAÇÃO AMBIENTAL NA PRESERVAÇÃO DO MEIO AMBIENTE
}

\author{
Rogério Alves Novaes, Fábio Ferreira Morong, Maria Helena Pereira Mirante, Márcia Lucchino \\ Universidade do Oeste Paulista - UNOESTE, curso de Direito, Presidente Prudente, SP. E-mail: \\ rogerio_novaes10@hotmail.com
}

\begin{abstract}
RESUMO
O presente trabalho abordou a importância da influência da educação ambiental junto à preservação do meio ambiente por meio de processos educativos voltados à base familiar, com intuito de se instituir uma conscientização jurídica e ambiental. O método aplicado foi o dedutivo legal, baseado na interpretação da Constituição Federal, legislação, jurisprudências, doutrinas e atos administrativos. Conclui-se que pela grande relevância da educação ambiental na tutela ambiental, principalmente através do processo educativo familiar, onde se espera que o indivíduo perceba que é parte integrante do meio e que existe a real necessidade de protegê-lo a fim de alcançar a sustentabilidade própria e das futuras gerações.

Palavras-chave: Educação ambiental. Preservação. Meio ambiente. Base Familiar

\section{THE INFLUENCE OF ENVIRONMENTAL EDUCATION ON THE PRESERVATION OF THE ENVIRONMENT}

\section{ABSTRACT}

This paper discusses the importance of the influence of environmental education along with the preservation of the environment through educational processes aimed at the family base, in order to institute legal and environmental awareness. The method applied to legal deduction, based on the interpretation of the Federal Constitution, legislation, jurisprudence, doctrines and administrative acts. It is concluded that due to the great relevance of environmental education in environmental protection, mainly through the family educational process, where it is expected that the individual will realize that it is an integral part of the environment and that there is a real need to protect it in order to achieve sustainability. And future generations.

Keywords: Environmental education. Preservation. Environment. Family Base.

\section{INTRODUÇÃO}

O direito ambiental está disposto na Carta Republicana de 1988 e não se trata de bem individual e nem coletivo, mas transindividual e indivisível, que se torna um direito fundamental. 0 artigo 225 da Constituição Federal define os responsáveis pela guarda e preservação deste direito, constando também o dever de se promover a educação ambiental em todos os níveis de ensino e a conscientização pública para a preservação do meio ambiente (inciso $\mathrm{VI}$ ), que se faz um elemento indispensável para a tutela do direito ambiental.

A educação ambiental é promovida pelo órgão gestor da Política Nacional de Educação Ambiental, o Ministério do Meio Ambiente, através do Programa Nacional de Educação Ambiental, que conta com diretrizes afim de garantir o respeito ao direito ambiental.

Contudo, a educação ambiental não é responsabilidade apenas do Estado, pois a educação como processo de conhecimento, formação de valores, costumes e cultura que há em cada família, deve estar introduzida por meio de educação voltada à base familiar transferida de geração a geração, eis que todos são beneficiários comuns do meio ambiente em seus aspectos gerais. 
O texto constitucional deixa claro em relação à solidariedade entre o Estado e a coletividade enquanto deveres e direitos, no entanto, transparece que tais responsabilidades seriam maiores para o Estado, que quase sempre não as cumpre. Por sua vez, o meio ambiente agrega todos os níveis de sistemas, englobando todos os organismos vivos e ecossistemas, na qual o próprio ser humano faz parte natural deste sistema e direito, ou seja, um direito de si mesmo, que se exercido de maneira equilibrada e sustentável, se perpetuará de gerações às gerações.

Desta forma, o presente trabalho tem o objetivo demonstrar a importância da influência da educação ambiental junto à preservação do meio ambiente por meio de processos educativos voltados à base familiar, com intuito de se instituir uma conscientização jurídica e ambiental. Ou seja, é imprescindível uma educação familiar adequada, com valores culturais direcionados ao meio ambiente, pois antes de haver um Estado, há uma sociedade, e antes desta, há uma família, que por sua vez, existe antes um indivíduo, e este faz parte da própria natureza.

\section{METODOLOGIA}

O método aplicado foi o dedutivo legal, baseado na interpretação da Constituição Federal, legislação, jurisprudências, doutrinas e atos administrativos.

\section{EDUCAÇÃO AMBIENTAL NA CONSTITUIÇÃO FEDERAL DE 1988}

Conforme Padilha (2010), a Carta Magna de 1988 dispõe em seu art. 225으, VI a configuração de um direito de terceira dimensão, na qual sua abrangência transcende a individualidade ou mesmo a coletividade, se fazendo em um direito metaindividual.

O constituinte de 1988 optou por tutelar além dos bem individuais, também os coletivos, e ainda uma terceira espécie, o "meio ambiente", pois consagrou-se no referido art. 2250 o direito ao meio ambiente ecologicamente equilibrado, que não é público nem particular, mas de uso comum, que em razão deste comando, constitui-se a Lei 8.078 de 1990, definindo os direitos metaindividuais, ou seja, os direitos difusos, coletivos e individuais homogêneos. (FIORILLO, 2015).

Neste sentido classificou-se o direito ao meio ambiente como um direito difuso, tendo em vista suas características de natureza indivisível e transindividualidade.

Se extrai do referido artigo dois verbos de comando em relação ao meio ambiente, que direcionam o encargo da "defesa" e da "preservação", ao poder público e a coletividade, ou seja, são responsáveis solidários pelo meio ambiente.

Assim está previsto no art. 225으 da CF:

[...] todos têm direito ao meio ambiente ecologicamente equilibrado, bem de uso comum do povo e essencial à sadia qualidade de vida, impondo-se ao Poder Público e à coletividade o dever de defendê-lo e de preservá-lo para as presentes e futuras gerações. (grifo nosso)

Como se observa, o legislador constituinte estabeleceu que a defesa e a preservação devem ser executadas não só pelo Estado mas também pelo povo. Segundo Mukai (2016), o art. 225 contempla o princípio da cooperação, quando se impõe ao Estado e a coletividade a defesa e preservação do meio ambiente.

O Estado, na sua ação de defesa, atuaria por meio de normas limitadoras e protetoras do meio ambiente, inibindo a sua degradação. E em relação a ação de preservação ambiental, efetivar-se-ia por meio de políticas educacionais visando a conscientização da importância do meio ambiente para a vida humana, com diretrizes incentivadoras a preservação do meio ambiente.

Já em relação as ações de defesa e preservação do meio ambiente pela sociedade, ocorreria através de uma proteção coletiva, onde todos tem o dever de cuidar, respeitar e divulgar a conscientização da preservação do meio ambiente, pois é um bem de uso comum de todos. 
Neste sentido, o legislador constituinte, vinculou o indivíduo na proteção direta e na manutenção indireta do meio ambiente.

Destarte, constata-se que a defesa e preservação do meio ambiente que estão previstas na Carta Magna ultrapassam os limites de uma simples compreensão jurídica, pois abarca uma conscientização social, que se concretiza por meio de uma educação direcionada a prática de uma cidadania ambiental, proporcionando um equilíbrio sustentável no meio ambiente, de forma a vigorar a qualidade de vida atual e futura. (PADILHA, 2010)

A conscientização social, de modo geral, se dá através de um processo de socialização dos indivíduos, na qual este processo pode ser denominado como educação, onde se faz imprescindível para a efetivação deste direito ao meio ambiente.

\section{ASPECTOS RELEVANTES DA POLÍTICA NACIONAL DE EDUCAÇÃO AMBIENTAL}

Em vista do ordenamento constitucional, o legislador instituiu a Política Nacional de Educação Ambiental (PNEA), por meio da Lei no 9.795 de 1999, na qual definiu a educação ambiental em seu art. 10:

Entendem-se por educação ambiental os processos por meio dos quais o indivíduo e a coletividade constroem valores sociais, conhecimentos, habilidades, atitudes e competências voltadas para a conservação do meio ambiente, bem de uso comum do povo, essencial à sadia qualidade de vida e sua sustentabilidade.

Esta lei estabeleceu ainda a competência, os princípios, os objetivos, as atividades e ações que devem ser desenvolvidas na execução da política nacional de educação ambiental, e posteriormente regulamentado o Programa Nacional de Educação Ambiental (ProNEA).

Oportuno salientar que o Ministério do Meio Ambiente avalia seu desempenho de atividades em ciclos, entre o primeiro dia de junho até o ultimo dia de maio do ano seguinte, definido por um índice de desempenho (IDIM) ${ }^{1}$, na qual, pode-se constatar que de 2012 até hoje, obteve índices progressivos e satisfatórios, contudo apresentou deficiência em relação aos planos de resíduos sólidos e recursos hídricos, exceto no último ciclo.

Por conseguinte, ainda quanto a educação ambiental, o Programa Nacional de Educação Ambiental possui as seguintes diretrizes: a) transversalidade, que visam a abertura de diálogos sobre políticas setoriais ambientais, entre o governo e a sociedade; b) o fortalecimento do Sisnama, ou seja, dentro das estruturas institucionais do Ministério do Meio Ambiente e do Ministério da Educação, compartilhando a ação do sistema nacional de meio ambiente; c) a sustentabilidade, no sentido de orientação dos agentes públicos e privados construindo exemplos de experiências para a sustentabilidade; d) a participação e controle social, que permitem a participação e o controle da sociedade, fomentando discussões, fiscalização, direcionadas as políticas ambientais, construindo valores culturais comprometidos com uma qualidade ambiental.

Destarte, é certo que a Política Nacional de Educação Ambiental coloca a educação ambiental como um componente essencial e permanente da educação nacional, devendo estar presente, de forma articulada, em todos os níveis e modalidades do processo educativo, em caráter formal e não formal.

\section{O PAPEL DA EDUCAÇÃO AMBIENTAL E O DIREITO AMBIENTAL}

A educação ambiental não é ação exclusiva do Estado, pois antes da questão ambiental está o processo de formação valorativa e cultural do ser humano, que se faz inicialmente dentro

\footnotetext{
${ }^{1}$ IDIM - Índice de Desempenho Institucional Médio, aferido com base na média aritmética dos índices de desempenho de cada meta definida, obtidos a partir do grau de alcance das respectivas metas.
} 
do seio familiar, que é o núcleo da sociedade. Portanto, assim como o Estado articula a questão ambiental no processo educativo formal, os indivíduos tem o dever de agregar valores, costumes e cultura voltadas à sustentabilidade, em preservação ao direito ambiental.

Grande exemplo de educação ambiental e de formação cultural, ocorreu na última copa do mundo quando torcedores japoneses, no término do jogo, antes de se ausentarem das arquibancadas, recolheram todos os resíduos dispensados na arquibancadas, durante o jogo, em uma notável demonstração de preocupação e respeito ambiental. Esta consciência ambiental dos japoneses, indiscutivelmente, não existe apenas por iniciativa de seu Estado, mas sim com uma participação efetiva do indivíduo, através de um processo educativo familiar passado de gerações em gerações.

Quanto a abrangência do direito ambiental ou mesmo o seu destinatário, a doutrina se divide entre os antropocêntricos (restritos), que entendem ser os destinatários apenas aqueles sujeitos detentores de direitos, ou seja, apenas o ser humano, não admitindo as futuras gerações pela falta de representação processual. já para os biocêntricos (extensiva), na qual nos perfilamos, entendem que o direito ambiental se destina a globalização equilibrada do sistema, abarcando todos os ecossistemas e biodiversidades, havendo uma rede complexa de deveres, garantindo um meio ambiente equilibrado e sadio para várias gerações e outras espécies de seres vivos.

Destarte, o direito ambiental é um direito natural que transcende em si mesmo, e o homem não é exclusivo nesse direito, de modo que o meio ambiente se reconhece pela proteção autônoma, com valor em si mesmo, na qual, o indivíduo tem o dever natural de respeitar as ordens naturais, que a exemplo dos japoneses, passam a educação ambiental de geração a geração, respeitando o meio ambiente e vivendo de forma harmônica e equilibrada.

Conforme Padilha (2010), a Carta Magna contempla um apelo para a comunhão de forças, entre o Estado e o povo, em prol da preservação e proteção do meio ambiente, onde isto somente é possível através de parcerias público-privadas, diálogos setoriais da sociedade, com solidariedade social.

O conceito jurídico constitucional do termo meio ambiente é indeterminado, e no âmbito natural, implica uma compreensão de todos os níveis de sistemas vivos, ou seja, os organismos, e ecossistemas, na qual, estes possuem suas próprias regras naturais que não se submetem em relação ao homem, porém, o homem deve respeitar, preservar e proteger estas regras, introduzindo no ordenamento jurídico.

E pelo ordenamento jurídico constitucional não se abstrai o comando educacional do homem em relação à natureza, pois a Carta Magna é clara em sua disposição quanto a responsabilidade solidária entre o Estado e povo, que se manifesta principalmente, ou quase que exclusivamente, através de uma política educacional, de forma a conscientizar o comportamento humano em relação ao meio ambiente, efetivando o princípio da participação na proteção deste direito.

\section{CONSIDERAÇÕES FINAIS}

O presente trabalho abordou a importância da influência da educação ambiental junto à preservação do meio ambiente por meio de processos educativos voltados à base familiar, com intuito de se instituir uma conscientização jurídica e ambiental.

Considerando a educação como um processo de transmissão cognitivo de valores, costumes e cultura, como também o meio ambiente um sistema em todos os níveis de ecossistemas, englobando todos seres vivos, este direito difuso classificado dentro de um entendimento biocêntrico em que o direito ambiental tutela um direito natural em si mesmo, constatou-se uma maior importância do elemento educativo na preservação do meio ambiente.

Verificou-se que o Estado conta com programas educativos no sentido de garantir a tutela ambiental através de seus respectivos órgãos, contudo, não alcança sua plenitude, pois na 
verdade este processo educacional deve ser exercido inicialmente pelo individuo, dentro do processo educativo familiar, pois esta é a base da sociedade, que por sua vez a base do Estado Democrático de Direito. Isto porque não basta apenas o Estado cumprir o seu papel educativo, pois o primeiro processo educativo ocorre dentro da família, a qual deve agregar a proteção à sustentabilidade do meio ambiente neste processo. É certo, portanto, que com apenas a atuação do Estado não se concretiza a referida tutela ao meio ambiente.

Portanto, é certo que a influencia da educação ambiental na preservação do meio ambiente está mais intimamente ligada a questão cultural, social e costumeira dos indivíduos, ou seja, dentro do processo educacional familiar, onde infelizmente o Brasil deixa muito a desejar. Não se pode encarregar apenas o Estado nesta tarefa, que por sua vez vem cumprindo seus deveres, na medida do possível, neste sentido educativo.

Por fim, conclui-se pela grande relevância da educação ambiental na tutela ambiental, principalmente através do processo educativo familiar, onde se espera que o indivíduo perceba que é parte integrante do meio e que existe a real necessidade de protegê-lo a fim de alcançar a sustentabilidade própria e das futuras gerações.

\section{REFERÊNCIAS}

AMARAL, P. S. Direito ao meio mbiente e proibição do retrocesso. São Paulo: Atlas, 2014. Disponivel em: <https://integrada.minhabiblioteca.com.br/\#/books/9788522489275/cfi/0!/4/2@100:0.00>. Acesso em: 08 jul. 2017.

BRASIL. Constituição (1988). Constituição da República Federativa do Brasil. Brasilia: Senado, 1988.

BRASIL. Código do consumidor. Lei no 8.078, de 11 de setembro de 1990. Brasília: Senado, 1990.

BRASIL. Política nacional de educação ambiental. Lei no 9.795, de 27 de abril de 1999. Brasília: Senado, 1999.

FIORILLO, C. A. P. Curso de direito ambiental brasileiro. 16. ed. São Paulo: Saraiva, 2015.

IBRAHIN, F. I. D. Educação ambiental: estudos dos problemas, ações e instrumentos para o desenvolvimento da sociedade. São Paulo: Érica, 2014. Disponivel em: <https://integrada.minhabiblioteca.com.br/\#/books/9788536521534/cfi/2!/4/4@0.00:8.79>.

Acesso em: 07 jul. 2017.

MINISTÉRIO DO MEIO AMBIENTE. Secretaria de articulação institucional e cidadania ambiental. Departamento de educação ambiental. Brasília: [s.n.], 2011. Disponivel em: <http://www.mma.gov.br/estruturas/educamb/_arquivos/balano_2009_2010_20.pdf>. Acesso em: 12 jul. 2017.

MINISTÉRIO DO MEIO AMBIENTE. Metas institucionais. [S.I.]: [s.n.]. Disponivel em: <http://www.mma.gov.br/metas-institucionais>. Acesso em: 12 jul. 2017. MINISTÉRIO DO MEIO AMBIENTE; MINISTÉRIO DA EDUCAÇÃO. Programa nacional de educação ambiental. Brasília: [s.n.], 2014. <http://www.mma.gov.br/images/arquivo/80221/pronea_4edicao_web-1.pdf>. Acesso em: 12 jul. 2017.

MUKAI, T. Direito ambiental sistematizado. 10. ed. Rio de janeiro: Forense, 2016. 
PADILHA, N. S. Fundamentos constitucionais do direito ambiental brasileiro. Rio de janeiro: Elsevier, 2010.

PHILIPPI JUNIOR, A.; PELICIONI, M. C. F. Eduacação ambiental. Barueri: Manole, v. 14, 2014. Disponivel em: <https://integrada.minhabiblioteca.com.br/\#/books/9788520445020/cfi/5!/4/4@0.00:40.6>. Acesso em: 07 jul. 2017.

ROCHA, J. C. D. S. D. Direito ambiental e meio ambiente do trabalho: dano, prevenção e proteção jurídica. São Paulo: LTr, 1997. 